\title{
The Magnitude, Types, and Roles of Social Support in Diabetes Management among Diabetics' in Southern Ethiopia: a Multilevel, Multicenter Cross-Sectional Study
}

Ebrahim Jaafaripooyan (D) Teshome Tesfaye Habebo (ID) ${ }^{1,2}$ Ali Mohammad Mosadeghrad (iD) Abbas Rahimi Foroushani (iD) ${ }^{3}$ Dawit G/Michael Anshebo (iD) ${ }^{4}$

'Department of Health Management and Economics, School of Public Health, Tehran University of Medical Sciences (TUMS),

Tehran, Iran (the Islamic Republic); ${ }^{2}$ Disease Prevention and Control Directorate, Kembata Tembaro Zone Health Department, Durame, SNNPRS, Ethiopia; ${ }^{3}$ Department of Epidemiology and Biostatistics, School of Public Health, Tehran University of Medical Sciences (TUMS), Tehran, Iran (the Islamic Republic); ${ }^{4}$ Public Health Emergency Management Directorate (PHEM), Kembata Tembaro Zone Health Department, Durame, SNNPRS, Ethiopia

\begin{abstract}
Introduction: Lifelong medical management is the main intervention to reduce diabetesrelated morbidities and premature deaths; yet, social support can be a vital intervention to improve diabetics' health. Therefore, this study aimed to determine the magnitude, types, and role of social support in diabetes management in southern Ethiopia.

Methods: A multi-stage systematic sampling was applied to recruit 634 adult diabetics from the three-tiered healthcare system in the region. We proportionally distributed the sample size between randomly selected ten health-care facilities across the hierarchy. Pretested questionnaires and checklist; Epi-Info, and SPSS software used for data collection; entry, and analyses, respectively, and the statistical significance was determined at a P-value $\leq 0.05$.

Results: A total of 240 females and 356 males completed the study, and the overall magnitude of the social support was $50.20 \%$ [95\% CI: $46.19 \%, 54.21 \%$ ], and it was categorized into non-material and material with $44.13 \%$ [95\% CI: $40.14 \%, 48.12 \%$ ] and $34.23 \%$ [ $95 \%$ CI: $30.42 \%, 38.04 \%$ ] magnitudes, respectively, and social support was left to the patients' families and friends whereas formal institutions and the public sectors were rarely offering when the patients needed it. Though sex, educational level, and health-care hierarchy were not significantly associated with the social support, residence, some occupations, presence of diabetic family members, acute medical conditions, blood glucose level, compliance to medical follow-ups, treatment adherence, and taking anti-diabetic drugs a day before the current visit to health-care facility were all statistically significantly associated with social support.
\end{abstract}

Conclusion: One of every two adult diabetic patients in southern Ethiopia was receiving any social support, and social support for diabetic people reduces medical follow-ups absenteeism, improves treatment adherence, glycemic level controlling, and helps lifestyle modifications. Therefore, to keep diabetic people healthy and achieve diabetes management goals, the Ethiopian healthcare system, institutions, and concerned stakeholders should strengthen the social support for diabetic patients.

Keywords: diabetes mellitus, disease management, magnitude, social support, southern Ethiopia

\section{Introduction}

Diabetes mellitus has become the major health threat for the global community, and this concern is mainly attributable to the increasing disease burden, devastating diabetic complications, loss of productivity, and high health-care costs. ${ }^{1}$ For
Correspondence: Teshome Tesfaye Habebo

Email teshometesfaye22@gmail.com 
example, global estimates indicated there were 151 million diabetics in 2000, and this figure increased by three folds, 463 million, between 2000 and 2019, and the developing countries contributed two-third of the global diabetes burden. Moreover, the projections show unless robust preventive measures are implemented to avert this trend, by 2030, the diabetes burden will rise to 578 million globally. $^{2}$

Ethiopia is one of the sub-Saharan African countries (SSA) where the diabetes burden is alarmingly increasing. For instance, in 2019, the number of diabetics in Ethiopia was 1.7 million that put the country among the top four leading African countries. However, the international diabetes federation's (IDF) projection indicates $68.10 \%$ of diabetic people in Ethiopia live undiagnosed, and every single hour nearly three peoples' deaths are attributable to diabetes mellitus. ${ }^{3}$

Ethiopia's low socio-economic status, growing demand for healthcare, high communicable diseases burden, increasing non-communicable diseases trends, and poor health-care services quality put the country among the nations with very poor health-related indicators. ${ }^{4-6}$ Lack of health-care services accessibility and affordability has also become significant challenges for millions of Ethiopians, specifically for the rural and urban poor communities.,

Thus, diabetes mellitus became one of the health threats of all population segments, particularly for the poor in developing nations like Ethiopia, and it brings unbearable burdens to the health, social and economic affairs of the people. ${ }^{7}$ Nevertheless, evidence indicates prevention of the disease progression, specifically the type II DM, is modestly achievable; and accessible and affordable health care for any DM type significantly decreases the negative effects too. ${ }^{8,9}$ For example, proper management of diabetes mellitus reduces admission rates, health-care costs, and premature death rates, and increases productivity, and improves the quality of life. ${ }^{2}$

However, in order to achieve the desirable diabetes management goals, cost-effective and ongoing clinical care, preventive practices, and person-centered goal setting and its implementation are more effective than managing the disease and its complications. To this effect, involving the diabetic patients' families, communities, significant others, and public sectors are vital for the patient to lead healthy and productive life (hereafter social support). ${ }^{7}$

Social support is an interpersonal bonding system that takes individuals at the center of the support and consists of several triangulating constituents and practices by both individuals themselves and other supporting bodies around them, ${ }^{10}$ and presented in (Figure 1). Besides, it involves self-evaluation of actual or perceived social ties with families, friends, relatives, colleagues, organizations, and/ or significant others that can offer emotional, material, monetary, or personal backing when required. ${ }^{11,12}$

Studies demonstrated that social support for diabetic patients is one of the enabling factors to accept and maintaining good self-care practices in diabetes management. ${ }^{13,14}$ People who perceive or ensure to have better social networks and support are more likely to demonstrate better health outcomes ${ }^{15}$ which is also specifically essential in predicting the implementation of healthy practices to manage chronic illnesses like diabetes mellitus. ${ }^{12}$

For instance, studies confirmed that social support for diabetics' was positively associated with blood glucose monitoring, good adherence to healthy diets, and doing regular physical exercises. Hence, social support for diabetic patients plays a vital role in enhancing diabetes selfmanagement behaviors and improving clinical outcomes. ${ }^{12}$ Moreover, better social support yields good health-related decision-making, implementation of healthy behaviors in chronic illness management, and good health status ${ }^{14,16}$ and it is one of the determinant factors to reduce diabetesrelated negative health consequences. ${ }^{17}$

To this effect, ongoing and focused social supports for diabetics' from self-help associations, governmental, nongovernmental, and faith-based organizations, families, and significant others can be very important and rewarding intervention, Nevertheless, social supports for diabetic patients is not well documented and there is a paucity of evidence on social support in Ethiopia and southern Ethiopia in particular. Therefore, this survey aimed to determine the magnitude, types, and role of social support in diabetes management among diabetic patients, in southern Ethiopia.

The finding of this study will play a vital role to establish evidence-based decision making to improve the health of the diabetic patients in the region in particular and beyond, and the study may be eye-opening research to see diabetes management as comprehensive, continues and participatory rather than merely focusing on clinical practices.

\section{Objectives of the Study General Objective}

- To determine the social support magnitude, types, and its roles in diabetes management among diabetic patients in southern Ethiopia. 


\section{Specific Objectives}

- To determine the magnitude of social support to diabetic patients in southern Ethiopia.

- To identify the major types of social support that diabetic patients receive in southern Ethiopia.

\section{Methodology Study Setting}

This study was conducted in south nations' nationalities and people's regional state (SNNPRS) of Ethiopia. Hawassa is the capital of SNNPRS, and the city is located at $280 \mathrm{~km}$ distance to the south of Addis Ababa (the capital city of Ethiopia). Two of the sixteen zones (subprovinces: Hadiya and Kembata Tembaro zones) were randomly selected, and the sub-province has dry, temperate, and cold climatic conditions. The main livelihood activities in the study area were un-mechanized agriculture, livestock rearing, and small businesses.

According to the region's finance and economic development bureau report, ${ }^{18}$ the $2020 / 21$ projected population was $2,690,735 ; 15.2 \%$ of the population were urban inhabitants, and $50.9 \%$ were females. ${ }^{18}$ Similar to the national administrative structures, each sub-province is administratively divided into districts (woredas), and there were 28 districts (7 urban and 21 rural) in the study area.

The region's public healthcare system, similar to the national one, is hierarchically organized into a three-tier system: tertiary (referral hospitals), secondary (general hospitals) and primary health-care units, PHCUs (which comprises primary hospitals, health centers, and health posts) in the descending order; except the health posts, all health-care levels deliver diabetes screening and clinical care; however, the service entry point and referral system begin at health centers, where only routine diabetes screening and blood glucose monitoring takes place, through referral hospitals, where specialty services are delivered, and the next upper level serves as an immediate referral center for its lower levels. In sum, there was one referral hospital, one general hospital, six primary hospitals, and 88 health centers, and 102 other health-care facilities such as drug stores and pharmacies in the subprovince. $^{19}$

\section{Study Design and Period}

A facilities-based cross-sectional study was carried out from May 01 to August 30, 2020.

\section{Study Population}

Adult diabetic patients who were on routine follow-ups in the health facilities during the study period

\section{Inclusion Criteria}

Diabetic patients who were on routine follow-ups at least for one year; age eighteen years and older, Ethiopian citizens, and patients who were willing to participate in the study.

\section{Exclusion Criteria}

Patients with communication barriers, psychiatric problems, and unable to communicate due to their underlying medical conditions were excluded.

\section{Sample Size Determination}

The sample size (n) required for this study was computed by using the formula to estimate a single population proportion, and the following assumptions were considered to calculate. A 50\% proportion (P), 95\% confidence level $\left(Z_{\alpha / 2}\right), 5 \%$ margin of sampling error $(d), 1.5$ design effect (D), and 10\% attrition rate (equation 1.1).

$$
n=\frac{\left((\mathrm{Z} \alpha / 2)^{2} * \mathrm{P}(1-\mathrm{P})\right) * \mathrm{D}}{\mathrm{d}^{2}}
$$

$\mathrm{n}=576$ plus 58 (the $10 \%$ attrition rate)

Hence, the sample size required to accomplish the study became 634 patients.

\section{The Data Collection Tools}

We used semi-structured questionnaires (for patient exit interviews) and checklists (for medical record reviewing). The tool was developed by reviewing the available literature and then contextualized by considering socio-economic, cultural and other related factors in the study area. ${ }^{1,4,7,10,20-23}$ The tools were prepared in English and translated into the Amharic language, the official language in the study area, and then back into the English language by two different expert translators and then pre-tested and improved accordingly.

\section{Sampling Procedure and Study Population Recruitment}

A multi-stage systematic sampling technique was employed to reach the study subjects. Initially, the study region was divided into 16 zones (sub-provinces). Two sub-provinces: Hadiya and Kembata Tembaro zones were selected by lottery method. The two zones were further divided into 28 districts. Eight of 28 districts were randomly chosen, and then all public health 


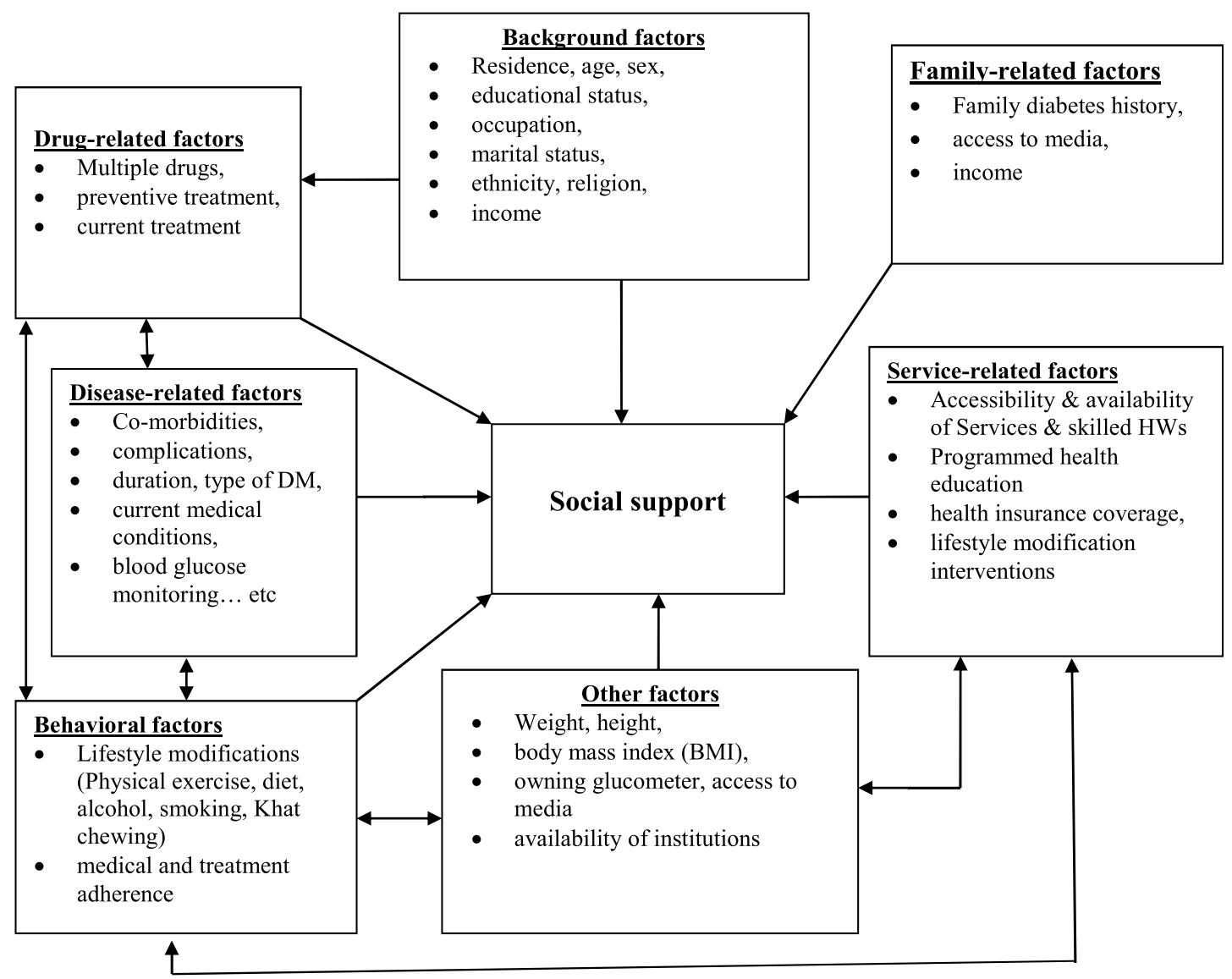

Figure I A conceptual framework on social support for diabetic patients in southern Ethiopia, 2020.

facilities in the selected districts were listed in a paper along with their hierarchies.

Then, the only referral hospital (Nigist Ileni Mohamed memorial referral hospital from Hadiya zone), and a general hospital (Dr. Bogalech Gebre memorial general hospital from Kembata Tembaro zone) were purposively chosen. Additionally, four out of the six available primary hospitals along with one of its five satellite health centers were selected randomly from the list. However, health posts were excluded from the list because the health posts do not give any DMrelated services to the patients. Based on their last six months' patient load, the sample size was proportionally distributed among the selected health facilities, and patients who came to the health facilities for routine follow-ups during the data collection period and satisfied the inclusion criteria were systematically selected and invited to participate voluntarily in the study.

\section{Data Collection Procedure}

After getting informed written consent from each patient, patients were allowed to choose one of the three commonly spoken languages as media of communication
(Amharic, Hadiyissa, or Kambatissa) depending on his/ her preference and ability to speak the languages, and then exit interviewing was done. At first sociodemographic related data were collected; to assess the magnitude of the social support single "yes/no" question was asked; and once the patient replied "Yes" to the question, then he/she was probed and asked to list the types and support giving bodies as much as possible. Finally, we reviewed each patient's medical record to get further information on disease history, medical conditions, treatment modality, and other relevant biomedical data.

\section{Data Management and Quality Control}

The questionnaire and checklist were developed based on the available literature and contextualized by considering the local contexts; double-blind translated and pre-tested. We recruited the research team and trained them on data collection procedures, tools, ethical considerations, and how to obtain informed consent. Additionally, strictly supervising, checking for consistency and completeness, and correcting the errors on-site or before starting the next day's data collection were carefully followed 
throughout the fieldwork. Data cleaning was done and we applied robust statistical software and methods.

\section{Study Variables \\ Dependent Variable}

Social support magnitude, types, and its role on diabetes management.

\section{Independent Variables}

Socio-demographic, clinical, behavioral, and all other variables, except the dependent variables, indicated in this study were treated as independent variables.

\section{Operational Definitions of Terms}

Social support was defined as any type of material (quantifiable aids, financial, instrumental ... etc.), and/or nonmaterial (unquantifiable, emotional, psychological ... etc.) supports given to the diabetic patients because he/she was a diabetic, from any social support-giving bodies as mentioned by each patient.

Social support-giving bodies include: the public sector, offices, diabetic patients' associations, family members, friends, colleagues, and other community institutions such as churches and mosques.

The glycaemic level was calculated by getting the last three consecutive scheduled visits' fasting blood glucose (FBG) mean values and considered as "Controlled" if the mean FBG value was $\leq 130 \mathrm{mg} / \mathrm{dL}$.

Good adherence to routine follow-up: if the patient attended on average $\geq 80 \%$ of the scheduled follow-ups during the last six months and vis-a-versa.

\section{Data Analysis}

Data entry was done in Epi-info version 3.5.1 and then exported into, cleaned, and analyzed in SPSS version 21.0. Descriptive statistics were calculated for all variables, and then bivariable analyses were done by applying the chi-square test and binary logistic regression to explore any association between each independent variable and the outcome variable. Finally, all variables with a P-value $\leq 0.05$ on bivariate analyses were selected and analyzed in the logistic regression model to ascertain the most significant determinants of the dependent variable while simultaneously adjusting for potential confounding factors at a P-value of $\leq 0.05$.

\section{Result}

\section{Socio-Demographic Characteristics of} Study Participants

A total of 634 adult diabetics were recruited as participants in this study, but 596 of them $(40.3 \%$ females and $59.7 \%$ males) completed the study. Eighty-four percent of the patients were in the age category of 18-60 years, and the patients' mean age was $45 \pm 14.65$ years. The vast majority of the study population 419 (70.30\%), were protestant Christians, and the rest: 84 (14.10\%), 42 $(7.10 \%), 40(6.70 \%)$, and $11(1.90 \%)$ were Orthodox, Catholic, Muslim, and other religions, respectively. More than two-thirds $(68.80 \%)$ of the study participants earn less than two US dollars per day, and nearly $15 \%$ of the patients were economically very dependent on families and/or significant others, and $51.85 \%$ of the study population has Radio or Television at his/her home. Still, 100\% out-of-pocket spending for medical care was $51.20 \%$ in the study area (Table 1 ).

\section{Health Status and Lifestyles Practices}

About $128(21.50 \%)$ of the study participants were type I diabetics, and the remaining 468 (78.50\%) were type II DM patients; type I DM was more prevalent among rural patients but type II diabetes was more common among patients from urban settings. Eighty-four percent of the study participants lived for less than ten years with diabetes, and only $66(11.10 \%)$ of the patients had ever participated in programmed diabetes education. Based on the national diabetes management protocol, 385 (64.6\%) study participants were eligible for statins preventive treatments but, only $36.10 \%$ of them received it. Moreover, 289 (48.49\%) study participants confirmed that they knew the availability of senior clinicians like internists in their respective health-care facilities, but unless they had emergency medical conditions, they never got an opportunity to consult the seniors during the last 12 months.

Concerning the risky lifestyle practices of the patients: before they knew their DM status, 98 (16.44\%), 203 (34.10\%), and $97(16.28 \%)$ of them were tobacco users, alcohol consumers, and Khat, a green leaf plant which contains Cathinone and associated with multiple health risks like causing damage to the endocrine system, ${ }^{24}$ chewers, respectively; however, once they knew their status and got help from others $6.30 \%$ of the tobacco users, 
Table I Socio-Demographic Characteristics of Diabetic Patients in Southern Ethiopia, 2020

\begin{tabular}{|c|c|c|c|c|}
\hline Variable & Category & $\mathbf{N}(\%)$ & Type I DM N (\%) & Type II DM N (\%) \\
\hline \multirow[t]{2}{*}{ Sex } & Female & $240(40.27)$ & $59(24.58)$ & I8I (75.42) \\
\hline & Male & $356(59.73)$ & $69(19.38)$ & $287(80.62)$ \\
\hline \multirow[t]{2}{*}{ Residence } & Rural & $283(47.48)$ & 7I (25.09) & $212(74.91)$ \\
\hline & Urban & $313(52.52)$ & $57(|8.2|)$ & $256(81.79)$ \\
\hline \multirow[t]{3}{*}{ Marital status } & Unmarried & $100(16.78)$ & 71 (7I.00) & $29(29.00)$ \\
\hline & Married & $44 \mid(73.99)$ & $56(12.70)$ & $385(87.30)$ \\
\hline & Widow or separated & $55(9.23)$ & I (I.82) & $54(98.18)$ \\
\hline \multirow[t]{3}{*}{ Education level } & No education & $146(24.50)$ & $14(9.59)$ & I $32(90.4 \mid)$ \\
\hline & Primary & $209(35.07)$ & $31(14.83)$ & $178(85.17)$ \\
\hline & Secondary \& above & $24 I(40.44)$ & $83(34.44)$ & $158(65.56)$ \\
\hline \multirow[t]{6}{*}{ Occupation } & Employed & $95(15.94)$ & $13(13.68)$ & $82(86.32)$ \\
\hline & Business & $120(20.13)$ & $14(11.67)$ & $106(88.33)$ \\
\hline & Farmer & $127(2|.3|)$ & $12(9.45)$ & 115 (90.55) \\
\hline & Housewife & $150(25.17)$ & $24(16.00)$ & $126(84.00)$ \\
\hline & Daily Laborer & $18(3.02)$ & $10(55.56)$ & $8(44.44)$ \\
\hline & Other & $86(14.43)$ & $55(63.95)$ & 31 (36.05) \\
\hline \multirow[t]{3}{*}{ Monthly Income } & $\leq 2279(<\$ 2)$ & $410(68.79)$ & $104(25.37)$ & $306(74.63)$ \\
\hline & $2280-5700(\$ 2-5)$ & $125(20.97)$ & $13(10.40)$ & $112(89.60)$ \\
\hline & $\geq 570$ I $(>5 \$)$ & $61(10.23)$ & $11(18.03)$ & $50(81.97)$ \\
\hline \multirow[t]{2}{*}{ Diabetic Family } & Present & $127(2|.3|)$ & $28(22.05)$ & 99 (77.95) \\
\hline & Absent & $469(78.69)$ & $100(21.32)$ & $369(78.68)$ \\
\hline \multirow[t]{3}{*}{ Current treatment } & OGLA & $265(44.46)$ & $0(0.00)$ & $265(100.00)$ \\
\hline & Insulin & $290(48.66)$ & $128(44.14)$ & $162(55.86)$ \\
\hline & OGLA + insulin & $4 \mathrm{I}(6.88)$ & $0(0.00)$ & $41(100.00)$ \\
\hline \multirow[t]{4}{*}{ Average BMI } & Normal & $370(62.08)$ & $87(23.5 \mathrm{I})$ & $283(76.49)$ \\
\hline & Underweight & $70(11.74)$ & $29(4 I .43)$ & $4 \mid(58.57)$ \\
\hline & Overweight & $128(21.48)$ & II (8.59) & $117(9 \mid .41)$ \\
\hline & Obese & $28(4.70)$ & I (3.57) & $27(96.43)$ \\
\hline \multirow[t]{2}{*}{ Own glucometer } & Yes & $87(14.60)$ & $14(16.09)$ & $73(83.91)$ \\
\hline & No & $509(85.40)$ & $114(22.40)$ & $395(77.60)$ \\
\hline \multirow[t]{2}{*}{ Treatment adherence } & Good & $357(59.90)$ & $99(27.73)$ & $258(72.27)$ \\
\hline & Poor & $239(40.10)$ & $29(12.13)$ & $210(87.87)$ \\
\hline \multirow[t]{2}{*}{ Yesterday took the treatment } & Yes & $559(93.79)$ & II 14 (20.39) & $445(79.61)$ \\
\hline & No & $37(6.21)$ & $14(37.84)$ & $23(62.16)$ \\
\hline \multirow[t]{2}{*}{ Sometimes feel Hassled taking Rx } & No & $277(46.48)$ & $74(26.7 I)$ & 203 (73.29) \\
\hline & Yes & $319(53.52)$ & $54(16.93)$ & $265(83.07)$ \\
\hline \multirow[t]{2}{*}{ Acute medical condition } & Absent & $221(37.08)$ & $70(31.67)$ & I5I (68.33) \\
\hline & Present & $375(62.92)$ & $58(15.47)$ & $317(84.53)$ \\
\hline \multirow[t]{2}{*}{ Mean fasting blood glucose } & Controlled & $279(46.8 I)$ & $70(25.09)$ & 209 (74.9I) \\
\hline & Uncontrolled & $317(53.19)$ & $58(18.30)$ & $259(81.70)$ \\
\hline \multirow[t]{2}{*}{ Medical follow-up adherence } & Good & $259(43.46)$ & $74(28.57)$ & $185(71.43)$ \\
\hline & Poor & $337(56.54)$ & $54(16.02)$ & $283(83.98)$ \\
\hline
\end{tabular}

Abbreviations: DM, diabetes mellitus; N, number; BMI, body mass index; OGLA, oral glucose level lowering agents; \$, USD. 
$24 \%$ of alcohol consumers and $9.20 \%$ of the Khat chewers dropped these practices. In contrast, no patient has reported that $\mathrm{s} /$ he had started practicing any of these risky behaviors after he/she was diagnosed with diabetes. Even so, Our study result on the patients' lifestyle modification practices indicated that $242(40.60 \%), 393$ (65.94\%), and $130(21.81 \%)$ of the patients did not follow healthy meal plans, did not do regular physical exercises, and sometimes stop taking treatment when they feel healthy, respectively, and 217 (36.41\%) of the patients self-rated their general health status as poor. Additionally, though $87(14.60 \%)$ of the patients own functional glucometer, only 32 (36.78\%) were regularly monitoring their blood glucose levels. Furthermore, the magnitude of uncontrolled blood glucose level, comorbidity, acute and chronic diabetic complications were $51.19 \%$, $54.87 \%, 63.26 \%$, and $51.34 \%$ in that order (Table 1).

\section{Social Support}

The magnitude of social support for diabetic patients in southern Ethiopia was 50.20\% (95\% CI: 46.31\%, 54.09\%), and mainly it has been received from families and close relatives or friends than from formal institutions. For instance, $149(25 \%)$ of the diabetic patients reported that they were members of the Ethiopian diabetic patients' Association (EDPA), yet, only $93(15.60 \%)$ of them get any support from the EDPA, and only $60(10.07 \%)$ of the patients stated that they sometimes receive some supports from the public sector.

Concerning the support types, our study result showed that non-material support was more prevalent than objective or material support: 263 (44.13\%) versus 204 $(34.23 \%)$, respectively. The support type matrix is presented in Table 2.

The role of social support on diabetes management was assessed by comparing and contrasting the "yes" answer against the "no" to the question on bivariate and multivariate analyses. Adjusted odds ratio (AOR), P-values, and 95\% CI were considered to determine their associations. For instance, even if it was not plausible on multivariable analysis, the odds of getting social support increased by $10 \%$ as the educational attainment advanced. It might be confounded with something that was not taken into consideration (Table 3). However, among the variables that showed association during the bivariable analyses model: Residence, occupation, presence of diabetic families, presence of any non-diabetic acute medical condition, blood glucose level, medical follow-up compliance, treatment adherence, and taking the anti-diabetes medicines yesterday became independent predictors of social support on multivariable analysis (Table 4).

\section{Discussion}

In this study, one of every two adult diabetic patients in southern Ethiopia receives any kind of social support when $\mathrm{s} /$ he needs it. This figure is comparable to prior study findings from Ethiopia, where the magnitude of social support for diabetics' ranged from $43.10 \%$ to $63.50 \%{ }^{25-27}$ and a study finding from Malaysia, where $51.30 \%$ of diabetic patients received it. ${ }^{20}$ In contrast, the current study finding opposes some other study reports from Ethiopia. ${ }^{28-31}$ The reasons for the discrepancies might be that, unlike the other surveys, this study assessed the magnitude of social support as its primary objective; involved a higher number of participants, and included patients from all the three hierarchies of the healthcare system.

Studies done elsewhere indicated that social support for diabetics' is one of the vital interventions to achieve the desirable DM management goals; it helps patients to maintain optimal glycemic level, adhere to lifestyle modifications, increases productivity, improves health, and which, in turn, improves the quality of life of the patients. $^{7,10,32}$ The result from our study also confirmed that the odds of having blood glucose level controlled, good treatment adherence, and taking the prescribed regimen a day before the current visit to health facility were each three times higher for patients who had received social support than those who did not and the odds of medical follow-up adherence was five times higher for patients who obtained social supports than those who did not get.

Similarly, the odds of getting social support for those patients from diabetic families and patients who had acute non-diabetic medical conditions were twice more than their counterparts. Therefore, it is crucial to strengthen social support for diabetic patients, which, in turn, will help to achieve the desired diabetes management goals.

On the other hand, the current study result indicated that a significantly higher proportion of social support for diabetic patients was given by patients' families, friends, or significant others than formal organizations, institutions, or public sectors. Furthermore, the types of social support given by these main actors significantly vary too. Thus, it looks like social support for diabetics' was almost left to patients' families and/or friends. 
Table 2 Tabular Presentation of Social Support Types for Diabetics' in Southern Ethiopia, 2020

\begin{tabular}{|c|c|c|}
\hline Support Giving Body & $\begin{array}{c}\text { Subjective or Non-Material Support } 263 \\
(44.13 \%)\end{array}$ & Objective or Material Support 204 (34.23\%) \\
\hline Patients' Families & $\begin{array}{l}\text { - Accompanying during HF visits } 24(4.0 \%) \\
\text { - Encouragement } 240(40.3 \%) \\
\text { - Health education } 18(3.0 \%) \\
\text { - Blood glucose monitoring/ measuring } 2(0.3 \%) \\
\text { - Giving reminder to take the treatment } 22(3.7 \%) \\
\text { - Psychological or emotional } 249(41.8 \%) \\
\text { - Informational support } 61(10.2 \%) \\
\text { - Foot inspection and other } 17(2.9 \%)\end{array}$ & $\begin{array}{l}\text { - Caregiving } 13(2.2 \%) \\
\text { - Diet management } 75 \text { (I2.6\%) } \\
\text { - Buying drugs and supplying } 69 \text { (II.6\%) } \\
\text { - Injecting Insulin } 9 \text { (I.5\%) } \\
\text { - Financial support } 187(31.4 \%) \\
\text { - Other materials assistances } 79 \text { (13.3\%) }\end{array}$ \\
\hline Diabetic patients' Association & $\begin{array}{l}\text { - Informational or Health education } 44(7.4 \%) \\
\text { - Drug distribution } 39(6.5 \%) \\
\text { - Emotional or psychological } 30(5.0 \%)\end{array}$ & $\begin{array}{l}\text { - Financial } 17(2.9 \%) \\
\text { - Supplying drugs, syringes } 18(3.0 \%) \\
\text { - Giving free reading materials and other } 36 \\
(6.0 \%)\end{array}$ \\
\hline $\begin{array}{l}\text { Other formal organizations or } \\
\text { institutions }\end{array}$ & $\begin{array}{l}\text { - Health education } 2(0.3 \%) \\
\text { - Psychological I }(0.2 \%) \\
\text { - Informational I } 3(2.2 \%) \\
\text { - Drug distributing I }(0.2 \%) \\
\text { - Keeping in touch through phone calls } 33(5.5 \%) \\
\text { - Making prayers for the patients } 48(8.1 \%) \\
\text { - Social networking and other } 20(3.4 \%)\end{array}$ & $\begin{array}{l}\text { - Drug supplying } 37(6.2 \%) \\
\text { - Financial I( } 0.2 \%) \\
\text { - expenses coverage and other } 7 \text { ( } 1.2 \%)\end{array}$ \\
\hline $\begin{array}{l}\text { Friends, colleagues, and significant } \\
\text { others }\end{array}$ & $\begin{array}{l}\text { - Accompanying during HF visits II (I.8\%) } \\
\text { Emotional I37 (23.0\%) } \\
\text { - Appraisal and understanding } 25(4.2 \%) \\
\text { - Listening to and following their needs I2 (2.0\%) } \\
\text { - Experience sharing } 88(14.8 \%) \\
\text { - Referring to others } 5(0.8 \%) \\
\text { - Keeping in touch through phone calls I80 (30.2\%) } \\
\text { - Informational } 36(6.0 \%) \\
\text { - Positive social interaction } 6 \mathrm{I}(\mathrm{I} 0.2 \%)\end{array}$ & $\begin{array}{l}\text { - Drug, syringe supplying } 7(\mathrm{I} .2 \%) \\
\text { - Social networking } 48(8.1 \%) \\
\text { - Financial \& other direct materials support } 75 \\
(12.6 \%)\end{array}$ \\
\hline
\end{tabular}

Our study finding showed that the odds of getting social support was roughly two times higher for patients from rural areas than those who were from urban settings; and even if it was not statistically plausible in our study, other studies demonstrated that social support positively influences self-management practices among males than females. $^{33}$

With regard to the study participants' occupations, employed (those people who are hired and getting monthly salaries from their employer like public or nonpublic sector) were less likely to receive any social support than those patients in the "others" category, which included students, jobless, and patients with disabilities. The higher odds of social support for other occupations may be associated with the fact that one-fifth of our study participants were economically very dependent on others and did not have any considerable incomes. Therefore, they might have looked for more support than the employed ones. Besides, in this study, the patients in the "other" categories were less educated than those employed; thus, they may be more aware of and hunted for social support.

According to our study, $21.31 \%$ of the study subjects confirmed the presence of at least one another diabetic family member. This result did agree with prior survey findings from Ethiopia ${ }^{31,34}$ but, it was inconsistent with others' findings. ${ }^{27,29}$ Additionally, the current study indicated that being from a diabetic family has increased the odds of receiving social support by two folds as compared to their counterparts. It might be related to becoming more familiar with diabetes and its care among people with diabetic family members and, this, in turn, might have improved the social support-seeking behaviors.

This study finding established that receiving any social support reduces absenteeism to diabetes management follow- 
Table 3 Factors Associated with Social Support for Diabetic Patients in Southern Ethiopia, 2020

\begin{tabular}{|c|c|c|c|c|c|c|}
\hline \multirow[t]{2}{*}{ Variable } & \multirow[t]{2}{*}{ Category } & \multicolumn{2}{|c|}{ Social Support } & \multirow[t]{2}{*}{ COR } & \multicolumn{2}{|c|}{ 95\% C.I } \\
\hline & & Yes & No & & Lower & Upper \\
\hline Sex & $\begin{array}{l}\text { Female } \\
\text { Male }\end{array}$ & $\begin{array}{l}|3| \\
168\end{array}$ & $\begin{array}{l}109 \\
188\end{array}$ & $\begin{array}{l}1.00 \\
1.34\end{array}$ & 0.97 & 1.87 \\
\hline Residence & $\begin{array}{l}\text { Rural } \\
\text { Urban }\end{array}$ & $\begin{array}{l}163 \\
136\end{array}$ & $\begin{array}{l}120 \\
177\end{array}$ & $\begin{array}{l}1.00 \\
1.77\end{array}$ & 1.28 & $2.45^{*}$ \\
\hline Age (in years) & $\begin{array}{l}\leq 29 \\
30-49 \\
\geq 50\end{array}$ & $\begin{array}{l}68 \\
100 \\
131\end{array}$ & $\begin{array}{l}35 \\
148 \\
114\end{array}$ & $\begin{array}{l}1.00 \\
2.88 \\
1.69\end{array}$ & $\begin{array}{l}1.78 \\
1.05\end{array}$ & $\begin{array}{l}4.65^{*} \\
2.73^{*}\end{array}$ \\
\hline Education level & $\begin{array}{l}\text { No education } \\
\text { Primary } \\
\text { Above primary }\end{array}$ & $\begin{array}{l}85 \\
97 \\
117\end{array}$ & $\begin{array}{l}61 \\
112 \\
124\end{array}$ & $\begin{array}{l}1.00 \\
1.61 \\
1.48\end{array}$ & $\begin{array}{l}1.05 \\
0.98\end{array}$ & $\begin{array}{l}2.47^{*} \\
2.24\end{array}$ \\
\hline Occupation & $\begin{array}{l}\text { Employed } \\
\text { Business } \\
\text { Farmer } \\
\text { Housewife } \\
\text { Daily laborer } \\
\text { Other }\end{array}$ & $\begin{array}{l}34 \\
55 \\
55 \\
88 \\
4 \\
63\end{array}$ & $\begin{array}{l}61 \\
65 \\
72 \\
62 \\
14 \\
23\end{array}$ & $\begin{array}{l}1.00 \\
0.66 \\
0.73 \\
0.39 \\
1.95 \\
0.20\end{array}$ & $\begin{array}{l}0.38 \\
0.42 \\
0.23 \\
0.59 \\
0.11\end{array}$ & $\begin{array}{l}1.14 \\
1.26 \\
0.67^{*} \\
6.40 \\
0.38^{*}\end{array}$ \\
\hline Monthly income (EBR) & $\begin{array}{l}\leq 2279 \\
2280-5700 \\
\geq 570 \text { I }\end{array}$ & $\begin{array}{l}223 \\
53 \\
23\end{array}$ & $\begin{array}{l}187 \\
72 \\
38\end{array}$ & $\begin{array}{l}1.00 \\
1.62 \\
1.97\end{array}$ & $\begin{array}{l}1.08 \\
1.13\end{array}$ & $\begin{array}{l}2.43^{*} \\
3.43^{*}\end{array}$ \\
\hline DM type & $\begin{array}{l}\text { Type I } \\
\text { Type II }\end{array}$ & $\begin{array}{l}78 \\
221\end{array}$ & $\begin{array}{l}50 \\
247\end{array}$ & $\begin{array}{l}1.00 \\
1.74\end{array}$ & 1.17 & $2.60 *$ \\
\hline Own glucometer & $\begin{array}{l}\text { Yes } \\
\text { No }\end{array}$ & $\begin{array}{l}35 \\
264\end{array}$ & $\begin{array}{l}52 \\
245\end{array}$ & $\begin{array}{l}1.00 \\
0.63\end{array}$ & 0.39 & $0.99 *$ \\
\hline Diabetic family & $\begin{array}{l}\text { Present } \\
\text { Absent }\end{array}$ & $\begin{array}{l}75 \\
224\end{array}$ & $\begin{array}{l}52 \\
245\end{array}$ & $\begin{array}{l}1.00 \\
1.58\end{array}$ & 1.06 & $2.35^{*}$ \\
\hline Mean fasting blood glucose & $\begin{array}{l}\text { Controlled } \\
\text { Uncontrolled }\end{array}$ & $\begin{array}{l}174 \\
125\end{array}$ & $\begin{array}{l}105 \\
192\end{array}$ & $\begin{array}{l}1.00 \\
2.55\end{array}$ & 1.83 & $3.54 *$ \\
\hline Medical follow-up adherence & $\begin{array}{l}\text { Good } \\
\text { Poor }\end{array}$ & $\begin{array}{l}188 \\
111\end{array}$ & $\begin{array}{l}71 \\
226\end{array}$ & $\begin{array}{l}1.00 \\
5.39\end{array}$ & 3.78 & $7.69 *$ \\
\hline Treatment adherence & $\begin{array}{l}\text { Good } \\
\text { Poor }\end{array}$ & $\begin{array}{l}219 \\
80\end{array}$ & $\begin{array}{l}138 \\
159\end{array}$ & $\begin{array}{l}1.00 \\
3.15\end{array}$ & 2.24 & $4.44 *$ \\
\hline Yesterday took the anti-diabetic treatment & $\begin{array}{l}\text { Yes } \\
\text { No }\end{array}$ & $\begin{array}{l}290 \\
9\end{array}$ & $\begin{array}{l}269 \\
28\end{array}$ & $\begin{array}{l}1.00 \\
3.35\end{array}$ & 1.55 & $7.24 *$ \\
\hline Any acute medical condition & $\begin{array}{l}\text { Present } \\
\text { Absent }\end{array}$ & $\begin{array}{l}204 \\
95\end{array}$ & $\begin{array}{l}171 \\
126\end{array}$ & $\begin{array}{l}1.00 \\
1.58\end{array}$ & 1.13 & $2.21 *$ \\
\hline Healthcare hierarchy & $\begin{array}{l}\text { Primary (PHCU) } \\
\text { Secondary } \\
\text { Tertiary }\end{array}$ & $\begin{array}{l}123 \\
77 \\
99\end{array}$ & $\begin{array}{l}135 \\
86 \\
76\end{array}$ & $\begin{array}{l}1.00 \\
1.02 \\
0.70\end{array}$ & $\begin{array}{l}0.69 \\
0.48\end{array}$ & $\begin{array}{l}1.51 \\
1.03\end{array}$ \\
\hline Self-rated general health status & $\begin{array}{l}\text { Good } \\
\text { Poor }\end{array}$ & $\begin{array}{l}182 \\
117\end{array}$ & $\begin{array}{l}203 \\
94\end{array}$ & $\begin{array}{l}1.00 \\
0.72\end{array}$ & 0.51 & 1.01 \\
\hline
\end{tabular}

Note: *Significantly associated at $P$-value $\leq 0.05$. 
Table 4 Determinants of Social Support for Diabetic Patients in Southern Ethiopia, 2020

\begin{tabular}{|c|c|c|c|c|c|c|}
\hline \multirow[t]{2}{*}{ Variable } & \multirow[t]{2}{*}{ Category } & \multicolumn{2}{|c|}{ Social Support } & \multirow[t]{2}{*}{ AOR } & \multicolumn{2}{|c|}{ 95\% C.I. } \\
\hline & & Yes & No & & Lower & Upper \\
\hline \multirow[t]{2}{*}{ Residence } & Rural & 163 & 120 & 1.00 & & \\
\hline & Urban & 136 & 177 & 1.65 & 1.07 & $2.54 *$ \\
\hline \multirow[t]{3}{*}{ Age (In Years) } & $\leq 29$ & 68 & 35 & 1.00 & & \\
\hline & $30-49$ & 100 & 148 & 1.74 & 0.83 & 3.68 \\
\hline & $\geq 50$ & $|3|$ & 114 & 0.77 & 0.35 & 1.68 \\
\hline \multirow[t]{3}{*}{ Education level } & No Education & 85 & 61 & 1.00 & & \\
\hline & Primary & 97 & 112 & 1.33 & 0.77 & 2.30 \\
\hline & Above Primary & 117 & 124 & 1.43 & 0.72 & 2.83 \\
\hline \multirow[t]{6}{*}{ Occupation } & Employed & 34 & 61 & 1.00 & & \\
\hline & Business & 55 & 65 & 0.50 & 0.22 & 1.12 \\
\hline & Farmer & 55 & 72 & 0.99 & 0.38 & 2.62 \\
\hline & Housewife & 88 & 62 & 0.48 & 0.18 & 1.25 \\
\hline & Daily Laborer & 4 & 14 & 2.53 & 0.50 & 12.84 \\
\hline & Other & 63 & 23 & 0.36 & 0.13 & $0.98 *$ \\
\hline \multirow[t]{3}{*}{ Monthly Income (EBR) } & $\leq 2279$ & 223 & 187 & 1.00 & & \\
\hline & $2280-5700$ & 53 & 72 & 1.02 & 0.53 & 1.96 \\
\hline & $\geq 5700$ & 23 & 38 & 1.18 & 0.48 & 2.90 \\
\hline \multirow[t]{2}{*}{ DM Type } & Type I & 78 & 50 & 1.00 & & \\
\hline & Type II & 221 & 247 & 1.26 & 0.66 & 2.38 \\
\hline \multirow[t]{2}{*}{ Own Glucometer } & Yes & 35 & 52 & 1.00 & & \\
\hline & No & 264 & 245 & 0.62 & 0.33 & 1.20 \\
\hline \multirow[t]{2}{*}{ Diabetic Family } & Present & 75 & 52 & 1.00 & & \\
\hline & Absent & 224 & 245 & 2.11 & 1.28 & $3.50 *$ \\
\hline \multirow[t]{2}{*}{ Mean fasting blood glucose } & Controlled & 174 & 105 & 1.00 & & \\
\hline & Uncontrolled & 125 & 192 & 2.66 & 1.77 & $3.98 *$ \\
\hline \multirow[t]{2}{*}{ Medical follow-up adherence } & Good & 188 & 71 & 1.00 & & \\
\hline & Poor & 111 & 226 & 5.44 & 3.54 & $8.36 *$ \\
\hline \multirow[t]{2}{*}{ Treatment adherence } & Good & 219 & 138 & 1.00 & & \\
\hline & Poor & 80 & 159 & 2.72 & 1.78 & $4.15^{*}$ \\
\hline \multirow[t]{2}{*}{ Yesterday took the anti-diabetic drug } & Yes & 290 & 269 & 1.00 & & \\
\hline & No & 9 & 28 & 2.86 & 1.12 & $7.30^{*}$ \\
\hline \multirow[t]{2}{*}{ Any acute medical condition } & Present & 204 & $|7|$ & 1.00 & & \\
\hline & Absent & 95 & 126 & 1.76 & 1.15 & $2.70 *$ \\
\hline
\end{tabular}

Note: *Significantly associated at P-value $\leq 0.05$.

Abbreviations: C.I., confidence interval; ETB, Ethiopian Birr; DM, Diabetes Mellitus.

ups by more than five times than those patients who did not get when they needed it. This finding supports other study findings from Malaysia ${ }^{20}$ and $\operatorname{Iran}^{21}$ where social support was positively associated with and improves medication adherence. Other existing studies also indicated that social support positively influences the patients' behaviors to manage and engage in healthy recommendations. ${ }^{23}$
Additionally, our study demonstrated that the odds of treatment adherence was nearly three times higher among patients who were getting social support than those who did not. This result is in line with previous study findings that showed a positive association between social support ${ }^{35}$ and, also, this study result substantiates a meta-analysis result done by DiMatteo MR that determined social support to 
diabetics' increases the likelihood of medication adherence by nearly two folds. ${ }^{36}$ Furthermore, the current study revealed that taking anti-glycemic drugs a day before the current interview date was positively associated with getting any social support. This is one more point that indicates any social support for diabetic patients plays a significant role in attaining desirable diabetes management goals.

The odd of having blood glucose levels controlled in our study was 2.7 times more likely among diabetic patients who received any support than patients who did not get it. This finding agrees with study findings from $\mathrm{China}^{37}$ and the United States of America ${ }^{23,38}$ where maintaining optimum glycemic level was associated with the availability of social support, and a narrative review from Iran also acknowledged that social support has a positive effect on glycemic level controlling among Iranian diabetics. ${ }^{32}$

Our study finding revealed that the odds of receiving any supports was 1.7 times higher among patients who had suffered from non-diabetic acute medical conditions than their healthier diabetic counterparts. It might be related to patients' higher perception, seeking and receiving the support they need when they encounter additional health issues.

\section{Conclusion}

In southern Ethiopia, one of every two adult diabetic patients received any social support when she/he needed it. And residence, some occupations, the presence of a diabetic family member, non-diabetic medical conditions, adherence to medical follow-ups, treatment adherence, having glycemic level controlled, and taking anti-diabetic drugs a day before the current visit to health-care facility were statistically significantly associated with social support.

Given that blood glucose level controlling and keeping good health status are multifaceted and determined by many internal and external factors, social support for diabetic patients plays a crucial role in minimizing and/or averting diabetic complications and other health and related impacts that may occur from poor diabetes management. Therefore, social support for diabetic patients is a fundamental intervention to improve their health and achieve desirable diabetes management goals.

Here we, in our strongest terms, recommend to Ethiopia's public healthcare system, governmental and nongovernmental institutions or organizations, and other stakeholders to join hands to reach the diabetic patients through social support, which, in turn, contributes to achieving the set sustainable development goals of reducing the noncommunicable diseases related mortality rates by 2030 .

\section{Strengths and Limitations of the Study}

This study exclusively depended on oral reports from the social support receivers that might have missed some data from the supply side (providers' side). And there might be social desirability biases and the cross-sectional nature of the study. However, we did our best to minimize the limitations. Apart from the limitations, this study was the first of its kind to be conducted on social support among diabetic patients in Ethiopia by recruiting patients from all the three-tiered health-care levels and applied a contextualized approach and robust statistical methods.

\section{Data Sharing Statement}

The data used to support the findings of this study are all included within the article, but whenever additional information or data is required, the corresponding author will provide it upon reasonable request.

\section{Ethical Considerations}

This study was conducted in accordance with the declaration of Helsinki. Tehran University of medical sciences institutional review board (TUMS-IRB) approved the study with a reference number IR.TUMS.SPH. REC.1398.078, and then the SNNPRS health bureau also approved the study, and each patient gave informed written consent to participate in the study.

\section{Acknowledgments}

We would like to acknowledge all the study participants, data collectors, data clerks, and supervisors without their active participation and commitments accomplishing the whole work would have been impossible. Our heartfelt gratitude goes to Tehran University of Medical Sciences (TUMS) and TUMS international campus (TUMS-IC) for giving this golden Ph.D. opportunity to TTH.

\section{Author Contributions}

TTH and EJP contributed in the conception, study design, execution, acquisition of data, analysis, interpretation, and have written the article; DGA has contributed in data acquisition, analysis, interpretation and substantially revised the article, and AMM and ARF contributed in the conception, study design and critically reviewed the article. All authors gave final approval of the version to be published; have agreed on the journal to which the article 
has been submitted, and agree to be accountable for all aspects of the work.

\section{Funding}

Tehran University of medical sciences partly funded this study, and the associated grant number was not applicable; however, the funder never had involved from the conception of the study through the decision to publish. Thus, we confirmed that there was no conflict of interest from the funder.

\section{Disclosure}

The authors report no conflicts of interest for this work.

\section{References}

1. Hosseingholizadeh N, Sadeghi R, Ardebili HE, Foroushani AR, Taghdisi MH. The correlation of self-efficacy and social support with social participation: a cross-sectional study among the elderly. J Med Life. 2019;12(3):239. doi:10.25122/jml-2019-0010

2. Federation ID. IDF Diabetes Atlas, 9th edn. Brussels, Belgium; 2019. Available from: https://www.diabetesatlas.org. Accessed May 20, 2021.

3. Federation ID. IDF Diabetes Atlas Africa, 9th edn. Brussels, Belgium; 2019. Available from: https://www.diabetesatlas.org. Accessed May 20, 2021.

4. Habebo TT, Takian A. Retrospective policy analysis of tobacco prevention and control in Ethiopia. Ethiop J Health Sci. 2020;30 (3):427-438. doi:10.4314/ejhs.v30i3.14

5. Michael G, Dagnaw W, Yadeta D, et al. Ethiopian national guideline on major NCDs 2016. The Federal Democratic Republic of Ethiopia, Ministry of Health; 2016.

6. Centers for Disease Control and Prevention; Center for Global Health; Division of Global Health Protection. CDC in Ethiopia:2018. Available from: https://stacks.cdc.gov/view/cdc/ 77516/cdc_77516_DS1.pdf. Accessed October 13, 2021.

7. Habebo TT, Pooyan EJ, Mosadeghrad AM, Babore GO, Dessu BK. Prevalence of poor diabetes self-management behaviors among Ethiopian diabetes mellitus patients: a systematic review and meta-analysis. Ethiop $J$ Health Sci. 2020;30(4):623-638. doi:10.4314/ejhs.v30i4.18

8. Abu-Rmeileh NM, Ghandour R, Mataria A, Awawda S, Jabr S, O'Flaherty M. Time to act on diabetes mellitus prevention in the West Bank, oPt: current and future direct cost of diabetes and its complications. Obes Med. 2017;6:18-22. doi:10.1016/j. obmed.2017.04.001

9. Ahmed M, Yirdachew E, Tefera G. Diabetic complications among follow-up patients: a cross-sectional study at Jimma University specialized hospital diabetic clinic. J Clin Mol Endocrinol. 2018;3(1):45.

10. Sun J, Shi B, Shi J, Yue X, Sun L, Tian Q, eds. The intervention effect assessment on social support condition of the first settlers in Dan Jiangkou reservoir area, China. MATEC Web of Conferences. EDP Sciences; 2017.

11. Debnam K, Holt CL, Clark EM, Roth DL, Southward P. Relationship between religious social support and general social support with health behaviors in a national sample of African Americans. J Behav Med. 2012;35(2):179-189. doi:10.1007/s10865-011-9338-4

12. Tang TS, Brown MB, Funnell MM, Anderson RM. Social support, quality of life, and self-care behaviors among African Americans with type 2 diabetes. Diabetes Educ. 2008;34(2):266-276. doi: $10.1177 / 0145721708315680$
13. Coffman MJ. Effects of tangible social support and depression on diabetes self-efficacy: a study of Hispanic older adults. $J$ Gerontol Nurs. 2008;34(4):32-39. doi:10.3928/00989134-20080401-02

14. Strom JL, Egede LE. The impact of social support on outcomes in adult patients with type 2 diabetes: a systematic review. Curr Diab Rep. 2012;12(6):769-781. doi:10.1007/s11892-012-0317-0

15. Uchino BN. Understanding the links between social support and physical health: a life-span perspective with emphasis on the separability of perceived and received support. Perspect Psychol Sci. 2009;4(3):236-255. doi:10.1111/j.1745-6924.2009.01122.x

16. Nicklett EJ, Heisler MEM, Spencer MS, Rosland A-M. Direct social support and long-term health among middle-aged and older adults with type 2 diabetes mellitus. J Gerontol B Psychol Sci Soc Sci. 2013;68(6):933-943. doi:10.1093/geronb/gbt100

17. Baek RN, Tanenbaum ML, Gonzalez JS. Diabetes burden and diabetes distress: the buffering effect of social support. Ann Behav Med. 2014;48(2):145-155. doi:10.1007/s12160-013-9585-4

18. SNNPRS-BoFED. South nation's nationalities and people's regional state (SNNPRS) bureau of finance and economic development, budget year plan for 2013 E.C. (2020/21). Hawassa, Ethiopia. (unpublished); 2020.

19. SNNPRS-HB. South nation's nationalities and people's regional state health bureau (SNNPRS-HB) annual regulatory data of 2013 E.C. Hawassa, Ethiopia; 2020.

20. Rashid AA, Zuhra H, Tan C. Social support, self-efficacy and their correlation among patients with Type 2 diabetes mellitus: a primary care perspective. Med J Malaysia. 2018;73(4):197-201.

21. Borhaninejad V, Shati M, Bhalla D, Iranpour A, Fadayevatan R. A population-based survey to determine the association of perceived social support and self-efficacy with self-care among elderly with diabetes mellitus (Kerman City, Iran). Int J Aging Hum Dev. 2017;85 (4):504-517. doi:10.1177/0091415016689474

22. Mondesir FL, White K, Liese AD, McLain AC. Gender, illness-related diabetes social support, and glycemic control among middle-aged and older adults. J Gerontol B Psychol Sci Soc Sci. 2016;71(6):1081-1088. doi:10.1093/geronb/gbv061

23. Bowen PG, Clay OJ, Lee LT, Vice J, Ovalle F, Crowe M. Associations of social support and self-efficacy with quality of life in older adults with diabetes. J Gerontol Nurs. 2015;41(12):21-29. doi:10.3928/00989134-20151008-44

24. Wabe NT. Chemistry, pharmacology, and toxicology of khat (Catha edulis forsk): a review. Addict Health. 2011;3(3-4):137.

25. Tiruneh GG, Abebe N, Dessie G. Self-reported hypoglycemia in adult diabetic patients in East Gojjam, Northwest Ethiopia: an institution-based cross-sectional study. BMC Endocr Disord. 2019;19(1):1-9. doi:10.1186/s12902-019-0341-z

26. Aschalew AY, Yitayal M, Minyihun A, Bisetegn TA. Self-care practice and associated factors among patients with diabetes mellitus on follow-up at University of Gondar Referral Hospital, Gondar, Northwest Ethiopia. BMC Res Notes. 2019;12(1):1-6. doi:10.1186/ s13104-019-4630-4

27. Chali SW, Salih MH, Abate AT. Self-care practice and associated factors among diabetes mellitus patients on follow up in Benishangul Gumuz Regional State Public Hospitals, Western Ethiopia: a cross-sectional study. BMC Res Notes. 2018;11(1):1-8. doi:10.1186/s13104-018-3939-8

28. Abate TW, Tareke M, Tirfie M. Self-care practices and associated factors among diabetes patients attending the outpatient department in Bahir Dar, Northwest Ethiopia. BMC Res Notes. 2018;11(1):1-5. doi:10.1186/s13104-018-3874-8

29. Dedefo MG, Ejeta BM, Wakjira GB, Mekonen GF, Labata BG. Self-care practices regarding diabetes among diabetic patients in West Ethiopia. BMC Res Notes. 2019;12(1):1-7. doi:10.1186/s13104-019-4258-4

30. Getie A, Geda B, Alemayehu T, Bante A, Aschalew Z. Self-care practices and associated factors among adult diabetic patients in public hospitals of Dire Dawa administration, Eastern Ethiopia. BMC Public Health. 2020;20 (1):1-8. doi:10.1186/s12889-020-09338-5 
31. Gurmu Y, Gela D, Aga F. Factors associated with self-care practice among adult diabetes patients in West Shoa Zone, Oromia Regional State, Ethiopia. BMC Health Serv Res. 2018;18(1):1-8. doi:10.1186/ s12913-018-3448-4

32. Rad GS, Bakht LA, Feizi A, Mohebi S. Importance of social support in diabetes care. J Educ Health Promot. 2013;2:62

33. Hunt CW, Wilder B, Steele MM, Grant JS, Pryor ER, Moneyham L. Relationships among self-efficacy, social support, social problem solving, and self-management in a rural sample living with type 2 diabetes mellitus. Res Theory Nurs Pract. 2012;26(2):126-141. doi:10.1891/1541-6577.26.2.126

34. Tiruneh SA, Ayele AA, Emiru YK, et al. Factors influencing diabetes self-care practice among type 2 diabetes patients attending diabetic care follow up at an Ethiopian General Hospital, 2018. J Diabetes Metab Disord. 2019;18(1):199-206. doi:10.1007/ s40200-019-00408-z
35. Mayberry LS, Osborn CY. Family support, medication adherence, and glycemic control among adults with type 2 diabetes. Diabetes Care. 2012;35(6):1239-1245. doi:10.2337/dc11-2103

36. DiMatteo MR. Social support and patient adherence to medical treatment: a meta-analysis. Health Psychol. 2004;23(2):207. doi:10.1037/0278-6133.23.2.207

37. Shao Y, Liang L, Shi L, Wan C, Yu S. The effect of social support on glycemic control in patients with type 2 diabetes mellitus: the mediating roles of self-efficacy and adherence. $J$ Diabetes Res. 2017;2017:1-8. doi:10.1155/2017/2804178

38. Mondesir FL. Illness-related diabetes social support and glycemic Control among middle-aged and older adults; 2013.

Diabetes, Metabolic Syndrome and Obesity: Targets and Therapy

\section{Publish your work in this journal}

Diabetes, Metabolic Syndrome and Obesity: Targets and Therapy is an international, peer-reviewed open-access journal committed to the rapid publication of the latest laboratory and clinical findings in the fields of diabetes, metabolic syndrome and obesity research. Original research, review, case reports, hypothesis formation, expert opinion and commentaries are all considered for publication. The manuscript management system is completely online and includes a very quick and fair peer-review system, which is all easy to use. Visit http://www.dovepress.com/testimonials.php to read real quotes from published authors. 